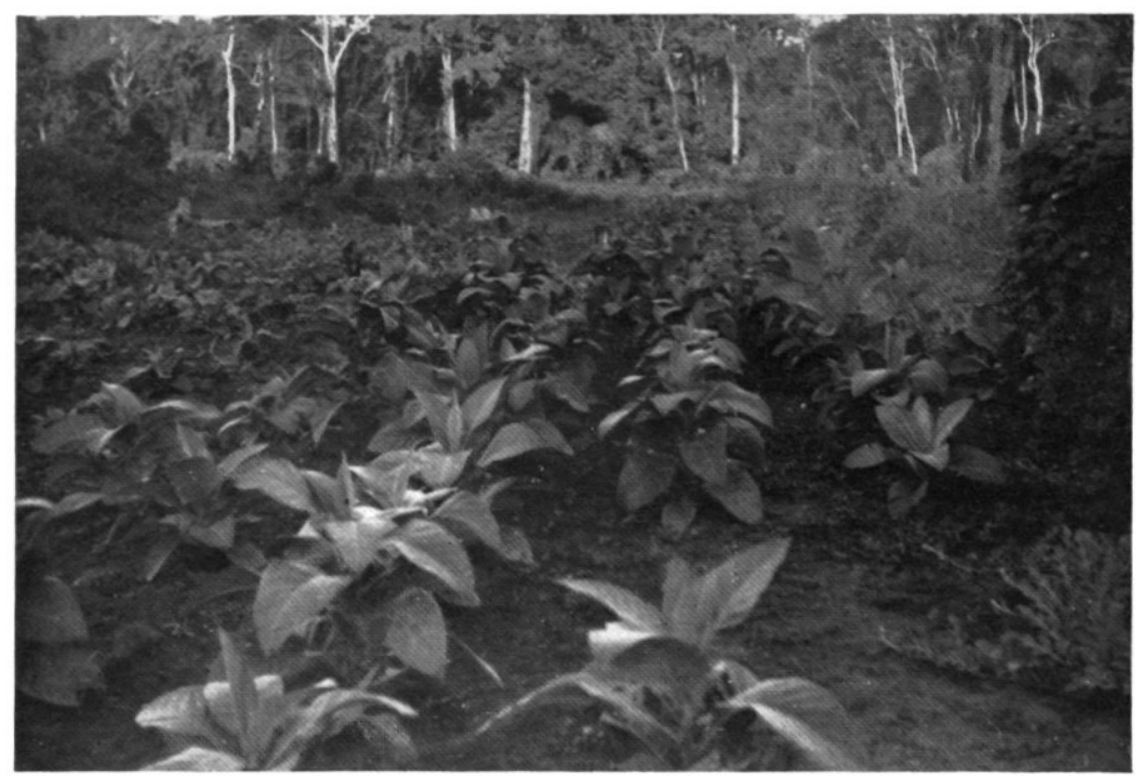

Fig. 1. Tabak-aanplant van een klein-landbouwer aan de Coppenameweg bij Coronie (1946). (Coll. Ind. Inst.. opn. W. L. Utermark).

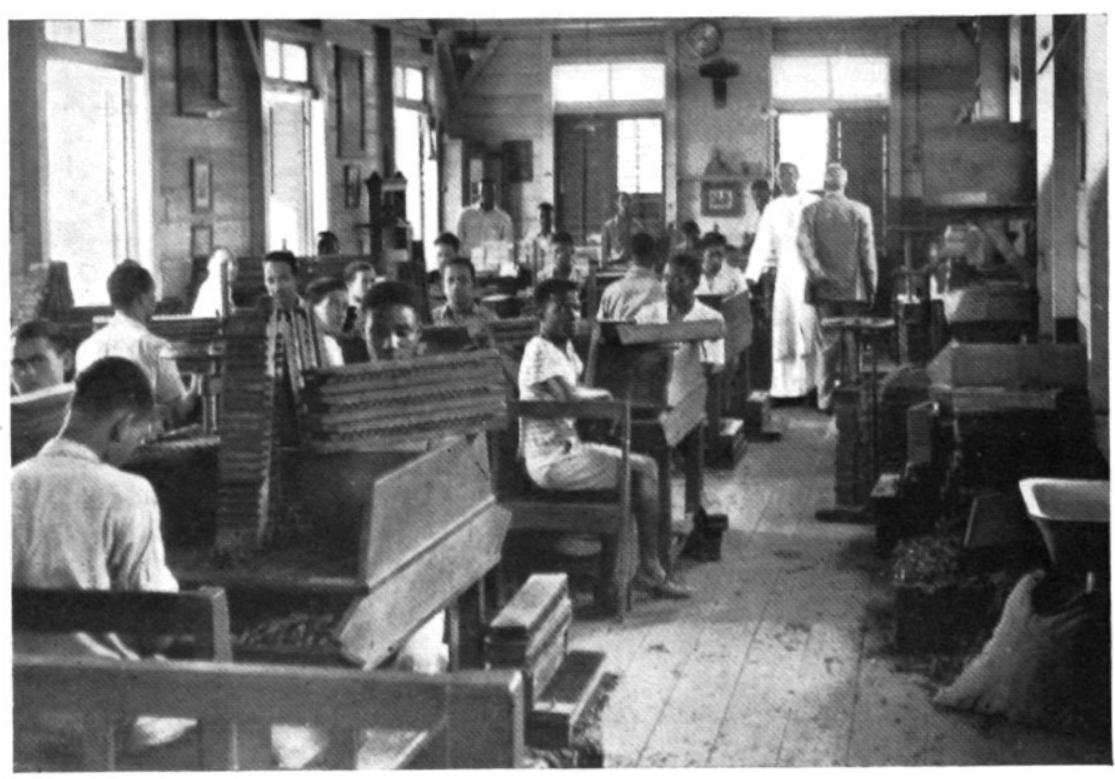

Fig. 2. Kijkje in de sigarenfabriek der Fraters van Tilburg aan de Verl. Gemene Landweg te Paramaribo (1946). (Coll. Ind. Inst., opn. W. L. Utermark) 


\title{
BEOORDELING VAN SURINAAMSE TABAK ${ }^{1}$ )
}

\author{
DOOR
}

IR. W. SPOON EN Wa. M. SESSELER, CHEM.DRA.

Sinds 1928 wordt in Suriname weder op bescheiden schaal tabak verbouwd. In de jaarverslagen eerst van het Departement Landbouwproefstation in Suriname ${ }^{2}$ ) en sinds 1936 in die van het Departement van Landbouw-Economische Zaken Suriname ${ }^{3}$ ) vindt men er geregeld melding van gemaakt. De tegenwoordige cultuur wordt voornamelijk door Javaanse klein-landbouwers beoefend in de centrale districten (verg. fig. 1). De ontwikkeling blijkt het beste uit de in tabel 1 bijeengebrachte productiecijfers ${ }^{4}$ ).

TABel I. Productie van tabak in Suriname

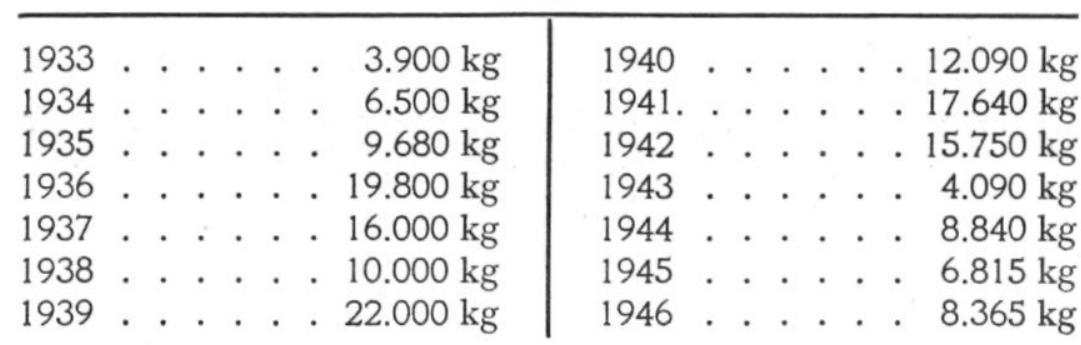

De tabak is z.g. bladtabak, die dus wel geschikt is voor kerftabak en sigaren, maar niet voor sigaretten. De in 1937 te Paramaribo opgerichte sigarettenfabriek van The British American Tobacco Company gebruikt dan ook geen inheemse maar ge-

1) Bericht van de Afdeling Tropische Producten (voorheen Handelsmuseum) van het Indisch Instituut, Amsterdam, No. 222

2) Verslag 1928-1930, 78 en 1931-1932, 64.

3) Verslag 1936-1937, 163; 1938-1939, 112; 1940, 46; 1941, 54 en 1942-1944, 38.

4) Ontleend aan de jaarversl. Kamer van Koophandel en Fabrieken Paramaribo.

$$
-321-
$$


importeerde tabak. Wel is dat het geval bij de locale sigarenfabricage, met name de reeds jaren bestaande Sigarenfabriek Leo Victor, toebehorende aan de Rooms-Katholieke Weesinrichting ,Boniface” en geleid door de Fraters van Tilburg (verg. fig. II), die in de laatste jaren de in tabel II vermelde hoeveelheden tabak heeft verwerkt ${ }^{1}$ ).

TABEL II. Fabriekmatige verwerking van tabak op sigaren, pijpen shagtabak in Suriname

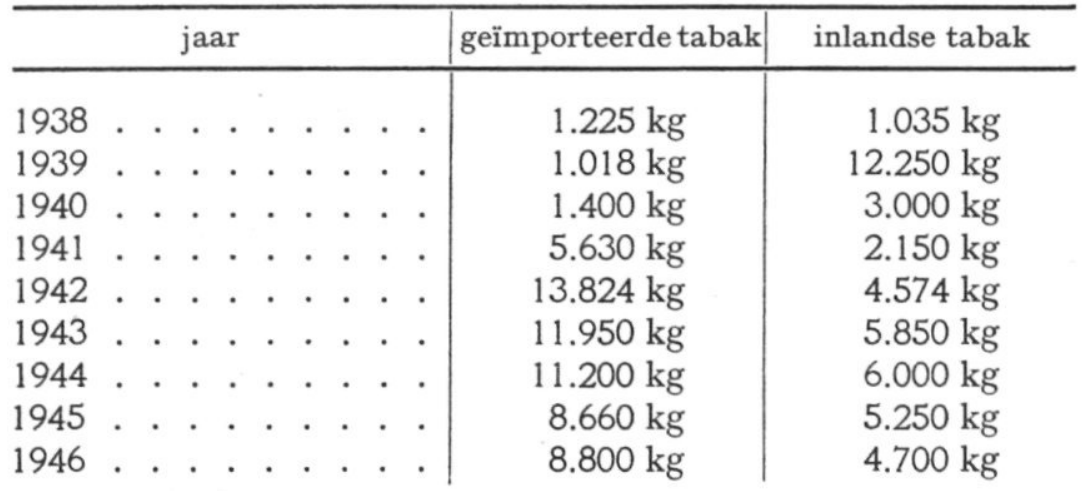

Bij vergelijking van de productie der inlandse tabak in tabel I met het verbruik in tabel II, blijkt, dat aanvankelijk maar weinig van de eigen tabaksoogst in de fabriek Leo Victor is verwerkt, maar dat dit in de latere jaren meer is geworden. Er is verder sinds 1941 een vrij constante verhouding waar te nemen tussen de hoeveelheden verwerkte geïmporteerde en Surinaamse tabak.

Hetgeen niet door de fabriek wordt afgenomen wordt door de klein-landbouwers gekorven in de handel gebracht.

Bij zijn studiereis naar Suriname en de Nederlandse Antillen in het najaar van 1946 besprak Ir. W. L. UTERMARK o.m. de tabaksteelt met verschillende landbouwconsulenten en met de bedrijfsleider van de reeds genoemde sigarenfabriek der Fraters Boniface ${ }^{2}$ ). Hij nam toen flinke monsters mede, terwijl naderhand Dr. D. S. Fernandes, directeur van het Departement van Landbouw-Economische Zaken, ons nog enige verdere mon-

1) Ontleend aan de jaarversl. Kamer van Koophandel en Fabrieken Paramaribo.

2) Jaarversl. Ind. Instituut 1946, 77. 
sters deed toekomen. In totaal beschikten wij zodoende over zes monsters, die tweezijdig onderzocht zijn, namelijk beoordeeld naar uiterlijk en smaak en naar de scheikundige samenstelling.

De wijze van voortbrenging (bevolkingsteelt) en het karakter (bladtabak) doen de Surinaamse tabak enigermate overeenkomen met de krosoktabak van Java. De vertegenwoordiger van de Indische Krosok Centrale in Nederland, de heer P. J. vAN DEN BROEK, die bij de Afdeling Handelsmuseum van het Indisch Instituut gedetacheerd was, leek ons dan ook in de eerste plaats in aanmerking te komen om aangezocht te worden voor beoordeling van de Surinaamse tabak. De uitslag is in tabel III bijeengebracht.

TABEL III. Beoordeling van monsters Surinaamse tabak

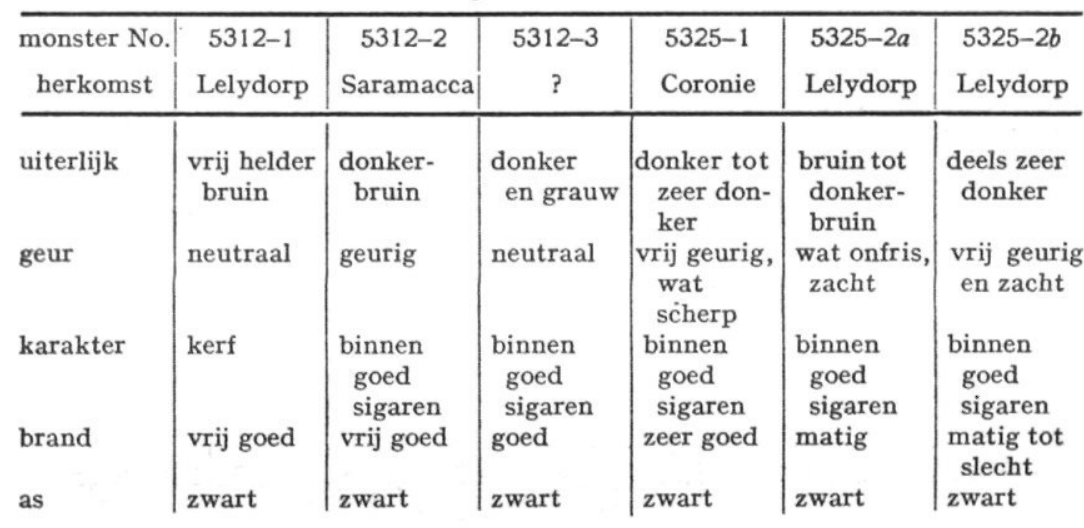

Daarbij werden de volgende meer algemene opmerkingen gemaakt. De tabak maakt bij alle monsters de indruk van primitief behandeld te zijn, de sortering is dienovereenkomstig matig tot slecht. In elk monster komen onrijp geplukte bladeren voor, die hier en daar groen zijn gebleven; de fermentatie is merendeels zeer onvoldoende.

Laatstgenoemde klacht is niet nieuw; de moeilijkheid zit in de omstandigheid, dat de individuele planter niet voldoende tabak voortbrengt om daaruit een behoorlijke fermenteerstapel te bouwen en dat pogingen van het departement om door samenvoegen van oogsten tot voor het fermenteren wel voldoende hoeveelheden te geraken, tot dusverre geen ingang vonden.

Desondanks valt het oordeel in tabel III nog mede, het karakter komt ook overeen met het gebruik, dat in de fabriek te Paramaribo van de eigen tabak wordt gemaakt.

Voor de scheikundige beoordeling van de Surinaamse tabak is gebruik gemaakt van de methodiek 1), die in ons laboratorium is

1) Meded. Dírecteur Tuinbouw II October 1948. 
uitgewerkt voor het onderzoek van in Nederland geteelde tabak voor de "Commissie voor onderzoek ten behoeve van de tabakscultuur" (voorzitter de Directeur van de Tuinbouw te 's-Gravenhage).

De daarbij bereikte resultaten zijn in tabel IV bijeengebracht; alle uitkomsten hebben betrekking op de luchtdroge tabak.

TABEL IV. Scheikundig onderzoek van monsters Surinaamse tabak

\begin{tabular}{|c|c|c|c|c|c|c|c|c|}
\hline $\begin{array}{l}\text { H.M. No. } \\
\text { herkomst }\end{array}$ & & & $\begin{array}{c}5312-1 \\
\text { Lely- } \\
\text { dorp }\end{array}$ & $\begin{array}{c}5312-2 \\
\text { Sara- } \\
\text { macca }\end{array}$ & $\begin{array}{c}5312-3 \\
?\end{array}$ & Coronie & $\begin{array}{c}5325-2 a \\
\text { Lely- } \\
\text { dorp }\end{array}$ & $\begin{array}{c}5325-2 b \\
\text { Lely- } \\
\text { dorp }\end{array}$ \\
\hline $\begin{array}{llll}\text { ocht } . . & . & . \\
\text { okgetal. } & . & . & \text {. }\end{array}$ & . & 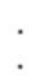 & $\mid \begin{array}{cc}9,2 & \% \\
70\end{array}$ & $\left|\begin{array}{cc}8,9 & \% \\
50 & \end{array}\right|$ & $\mid \begin{array}{ll}11,1 & \% \\
40\end{array}$ & $\mid \begin{array}{cc}4,0 & \% \\
55 & \end{array}$ & $\begin{array}{l}4,6 \% \\
50\end{array}$ & $\% \begin{array}{ll}4,9 & \% \\
60 & \end{array}$ \\
\hline $\begin{array}{l}\text { nicotine . . . } \\
\text { stikstof-totaal. } \\
\text { stikstof-eiwit . . }\end{array}$ & $\begin{array}{l}\dot{ } \\
\dot{ }\end{array}$ & . & $\begin{array}{l}1,52 \% \\
2,15 \% \\
2,10 \%\end{array}$ & $\begin{array}{l}0,40 \% \\
2,76 \% \\
2,39 \%\end{array}$ & $\begin{array}{l}0,33 \% \\
2,18 \% \\
2,03 \%\end{array}$ & $\begin{array}{l}1,76 \% \\
3,40 \% \\
2,15 \%\end{array}$ & $\begin{array}{l}0,58 \% \\
3,12 \% \\
2,42 \%\end{array}$ & \begin{tabular}{l|l} 
& $1,20 \%$ \\
$3,55 \%$ \\
0
\end{tabular} \\
\hline $\begin{array}{l}\text { suiker, oplosbaar, } \\
\text { vóór hydrolyse } \\
\text { „polyphenolen". } \\
\text { ruw vezel. . . . }\end{array}$ & $\begin{array}{l}\dot{ } \\
\dot{.}\end{array}$ & . & $\begin{array}{r}0,33 \% \\
1,52 \% \\
11,7 \%\end{array}$ & $\begin{array}{r}0,34 \% \\
1,08 \% \\
12,4 \%\end{array}$ & $\begin{array}{r}0,37 \% \\
1,21 \% \\
13,5 \%\end{array}$ & $\begin{array}{r}0,25 \% \\
0,50 \% \\
13,8 \%\end{array}$ & $\begin{array}{r}0,28 \% \\
0,97 \% \\
13,5 \%\end{array}$ & \begin{tabular}{r|r}
$0,45 \%$ \\
0 \\
0 \\
$0,36 \%$ \\
$14,4 \%$
\end{tabular} \\
\hline $\begin{array}{l}\text { pн. . . . . . } \\
\text { hars. . . . . }\end{array}$ & . & & $\begin{array}{ll}6,9 & \\
5,3 & \%\end{array}$ & $4,7 \%$ & $\begin{array}{ll}9,2 & \\
5,4 & \%\end{array}$ & $\begin{array}{ll}7,2 & \\
6,1 & \%\end{array}$ & $\mid \begin{array}{ll}8,4 & \\
6,4 & \%\end{array}$ & $\begin{array}{l}7,3 \\
6,6 \%\end{array}$ \\
\hline $\begin{array}{lll}\text { as . } & . \\
\text { "pure as". } & . \\
\text { as-analyse: } & \mathrm{Cl} . \\
& \\
& \mathrm{MgO} \\
& \mathrm{CaO} .\end{array}$ & . & . & $\left|\begin{array}{rr}21,7 & \% \\
77,2 & \% \\
6,0 & \% \\
4,0 & \% \\
9,5 & \%\end{array}\right|$ & $\left|\begin{array}{rr}29,4 & \% \\
58,9 & \% \\
7,8 & \% \\
5,3 & \% \\
7,9 & \%\end{array}\right|$ & $\left|\begin{array}{rr}21,3 & \% \\
97,3 & \% \\
1,2 & \% \\
2,6 & \% \\
20,9 & \%\end{array}\right|$ & $\left|\begin{array}{rr}32,5 & \% \\
99,3 & \% \\
5,2 & \% \\
4,0 & \% \\
27,2 & \%\end{array}\right|$ & $\left|\begin{array}{rr}23,5 & \% \\
94,1 & \% \\
10,1 & \% \\
8,3 & \% \\
6,1 & \%\end{array}\right|$ & \begin{tabular}{r|r}
18,5 & $\%$ \\
97,5 & $\%$ \\
18,2 & $\%$ \\
11,3 & $\%$ \\
7,1 & $\%$
\end{tabular} \\
\hline $\begin{array}{l}\text { Dokonderzoek, } \\
\text { luchtdroge tal }\end{array}$ & & & & & & & & \\
\hline $\begin{array}{llll}\mathrm{pH} & . & . & . \\
\text { ammoniak } & . & . & . \\
\text { nicotine } & . & . & .\end{array}$ & $\cdot$ & & $\begin{array}{l}9,5 \\
1,15 \% \\
0,33 \%\end{array}$ & $\left|\begin{array}{l}9,5 \\
1,07 \% \\
0,18 \%\end{array}\right|$ & $\begin{array}{l}9,3 \\
1,07 \% \\
0,15 \%\end{array}$ & $\begin{array}{l}8,9 \\
2,41 \% \\
0,72 \%\end{array}$ & $\begin{array}{l}8,7 \\
2,13 \% \\
0,30 \%\end{array}$ & \begin{tabular}{l|l} 
& 9,0 \\
0 & $2,29 \%$ \\
0 & $0,34 \%$
\end{tabular} \\
\hline
\end{tabular}

De uitkomsten kunnen verder als volgt worden toegelicht.

Het rookgetal is hoog en typerend voor kerf- en sigarentabak (alkalische groep). Een parallelliteit van die waarden met het nicotinegehalte, zoals dat wel eens gedacht wordt, valt niet waarte nemen.

Het nicotinegehalte zelf varieert nogal bij deze monsters; dit is ook te verwachten bij monsters van verschillende planters en afkomstig van zaad van wellicht verschillende varieteiten.

In overeenstemming met het tabakstype vinden wij een gemiddelde verhouding eiwit-suiker van ruim $6: 1$; dit is nogal hoog, maar overeenkomend met dezelfde verhouding bij tabak afkomstig van Java. 
Het totaal-stikstofgehalte ligt ongeveer even hoog als bij Nederlandse tabak, zoals die gedurende de tweede wereldoorlog hier te lande werd geteeld, terwijl het percentage eiwit hoger ligt; de verhouding van die gehalten nadert zodoende de waarde voor Java-tabak.

Het suikerpercentage, berekend als glucose, is nogal gelijkmatig van hoogte; het gehalte aan ,"polyphenolen” (berekend als glucose) loopt echter aanzienlijk uiteen.

Voor dit soort rooktabak is het ruw-vezelgehalte normaal.

$\mathrm{De} \mathrm{pH}$ is opvallend hoog (6.9-9.2), misschien een gevolg van de bodemtoestand ter plaatse. Bij Nederlandse tabak varieerde die waarde van 5,6 tot 6,2 , gemiddeld 5,8 ; bij tabak uit de Oosthoek van Java, onderzocht kort na de oorlog, vonden wij gemiddeld 6,7 à 6,8, dus steeds zwak zuur.

Het harsgehalte is gemiddeld $5,8 \%$, overeenkomend met dat van de Nederlandse tabak (gemiddeld 5,6\%), echter wat lager dan bij Java-tabak, waar wij gemiddeld $6,5 \%$ vonden. Laatstgenoemde tabak is daardoor geuriger dan de Surinaamse.

Een belangrijk punt bij tabak is de brandbaarheid. Daarvan is het één en ander te vertellen op grond van het asgehalte en de samenstelling van de as. Een minder goede brand is o.m. een gevolg van een hoog chloorgehalte $(\mathrm{Cl})$. Zulks werd reeds waargenomen door Dr. H. J. Muller bij zijn onderzoek van tabakken afkomstig van een proefveld in de nabijheid van Domburg en van de plantage De Morgenstond 1).

Anders echter was ditmaal het calcium- en magnesiumgehalte ( $\mathrm{CaO}$ resp. $\mathrm{MgO}$ ). Bij een tweetal monsters vinden wij de typische eigenschappen der Surinaamse kustgrond terug, te weten een hoger magnesium- dan calciumgehalte. Bij de vier andere monsters is dat niet zo. Vermoedelijk had men de betrokken terreinen beter gedraineerd, mogelijk is ook nog bemesting toegepast, waardoor de oorspronkelijke magnesium-calciumverhouding niet meer is terug te vinden en een betere brand is verkregen. Wel is het asgehalte in een enkel geval zeer hoog geworden (T.P. No. 5325-1).

$\mathrm{Bij}$ het beschouwen van de cijfers, verkregen bij de rookanalyse, valt het meest op, dat in verhouding tot het nicotinegehalte van de tabak het percentage nicotine in de rook nogal laag is $(20-55 \%$ van het oorspronkelijke gehalte). Vergeleken met de betrokken cijfers bij Nederlandse tabak $(50-85 \%)$, is die verhouding heel gunstig te noemen. De waarden komen dan ook overeen met die van Java-tabak. Zowel de $\mathrm{pH}$ als het ammoniakgehalte van de rook zijn zeer hoog. Voor de door ons onderzochte Indische tabak geldt die opmerking wat betreft de $\mathrm{pH}$ eveneens, echter ligt dan het ammoniakgehalte lager, ook in verhouding tot het totaal stikstof-gehalte van de tabak.

Het oordeel van den expert en de uitslag van het scheikundig onderzoek bevestigen elkaar. In overeenstemming met de reeds geuite veronderstelling zijn wij geneigd deze Surinaamse tabak,

1) Dept. Landb. Econ. Zaken, verslag over 1941, 37. 
wat type betreft, te vergelijken met de Javaanse krosoktabak. Voortzetting van de cultuur verdient dan ook zeker aanbeveling, vooral wanneer van overheidswege voortgegaan kan worden met het geven van landbouwkundige en technische adviezen. Wat de bereiding aangaat zal de fermentatie in betere en geregelder banen geleid dienen te worden.

Wij bevinden ons daarbij in overeenstemming met de conclusies van de Commissie voor bestudering van na-oorlogse problemen in Suriname, die in 1943 werd ingesteld en in Mei 1945 haar rapport uitbracht. Aangezien dat rapport wellicht niet algemeen bekend is, laten wij de desbetreffende passage van blz. 40 hier volgen:

„Deze cultuur biedt nog vele mogelijkheden. In het bijzonder geldt dit voor de Oost-Indische bevolking, daar de verbouw van dit gewas zeer intensief behoort te geschieden, hetgeen het meest in overeenstemming is met de geaardheid van den Javaan. De tabakscultuur dient gepropageerd te worden als een gewas voor den klein-landbouwer en wel op die gronden welke zich daartoe leenen (zandgronden). Getracht moet worden door het verstrekken van zaaimateriaal van zoodanige soorten, welke hier verwerkt kunnen worden, de belangstelling voor deze cultuur op te wekken. Aan een en ander dienen uitgebreide proefnemingen vooraf te gaan, zoowel waar het betreft de te verbouwen variëteiten als het verwerken van het product, daar het aantal inheemsche soorten legio is doch de kwaliteit zoodanig dat geen afzet op ruimere schaal gevonden kan worden op de binnenlandsche markt".

Op deze betekenis van de voorziening in eigen behoefte wezen ook wij aan de hand van de cijfers in tabel II.

Amsterdam, Juli 1948. 


\section{APPRECIATION OF TOBACCO FROM SURINAM}

BY

W. SPOON AND WA. M. SESSELER

(Tropical Products Section of the Royal Institute for the Indies, Amsterdam).

\section{SUMMARY}

A description is given of the cultivation of tobacco in Surinam, which is nowadays almost entirely in hands of the Javanese small holders (immigrants). Figures of the production since 1933 are given in table I.

The tobacco is not suitable for the manufacture of cigarettes, but can very well be used for cigars and pipe tobacco. The factory in Paramaribo of smoking commodities (cigars, pipe tobacco and shag) uses a mixture of imported and home grown tobacco. Figures are given in table II. There is no export of tobacco.

Six samples from various small holdings were examined, first according to appearance and taste, then in the chemical laboratory. The results are given in two tables (III and IV).

There appears to be several faults, the treatment of the leaves is rather primitive and the fermentation decidedly insufficient.

The type of the tobacco bears some resemblance to the tobacco cultivated by the natives in Java, the socalled Krosok tobacco.

With the aid of the Government it will surely be possible to improve and extend the tobacco culture. 